\title{
Prognostic Significance of Glutathione Peroxidase Levels (GPx1) in Head and Neck Cancers
}

\author{
Didier Dequanter ${ }^{1,2}$, Ruveyda Dok ${ }^{1}$, Louet Koolen ${ }^{1}$, Vincent Vander Poorten ${ }^{3}$ \\ and Sandra Nuyts ${ }^{1,4 *}$
}

${ }^{1}$ Laboratory of Experimental Radiotherapy, Department of Oncology, KU Leuven, Belgium, ${ }^{2}$ Department of Head and Neck Surgery, CHU Saint Pierre, Brussels, Belgium, ${ }^{3}$ Otorhinolaryngology, Head and Neck Surgery, Department of Oncology, Section Head and Neck Oncology, University Hospitals Leuven, KU Leuven, Leuven, Belgium, ${ }^{4}$ Department of Radiation Oncology, Leuven Cancer Institute, University Hospitals Leuven, Leuven, Belgium

\section{OPEN ACCESS}

Edited by:

Jesper Grau Eriksen,

Odense University Hospital, Denmark

Reviewed by:

Mohamed Saad Zaghloul, Cairo University, Egypt

Pernille Lassen,

Aarhus University Hospital, Denmark

Joel S. Greenberger,

University of Pittsburgh Medical

Center, USA

*Correspondence:

Sandra Nuyts

sandra.nuyts@uzleuven.be

Specialty section:

This article was submitted to Head and Neck Cancer,

a section of the journal

Frontiers in Oncology

Received: 05 March 2017 Accepted: 18 April 2017

Published: 09 May 2017

Citation:

Dequanter D, Dok R, Koolen L, Vander Poorten V and Nuyts S (2017)

Prognostic Significance of Glutathione Peroxidase

Levels (GPX1) in Head and Neck Cancers.

Front. Oncol. 7:84.

doi: 10.3389/fonc.2017.00084
Introduction: To date, no reliable prognostic biological marker for all squamous cell carcinoma located in different subsites of the head and neck region has been identified and used in daily routine. In line with our previous studies, in which we showed a role of glutathione and associated enzymes as potential biological markers, we investigated the relationship between GPx1 and prognosis of head and neck squamous cell carcinoma.

Methods: The association between GPx1 and patient and tumor related factors were investigated in 87 pretreatment biopsies from head and neck cancer patients treated by (chemo)radiation. Moreover, the influence of GPx1 expression on outcome parameters was assessed.

Results: A significant difference was found in the T-stage between the low and highexpressing GPx1 groups. About 75\% of the T3-T4 tumors were considered GPx1 low-expressing tumors, while low GPx1 expression was only seen in 25\% of the T1-T2 tumors. There was also a significant difference found between the groups when looking at the different tumor sites. Local control, locoregional control, disease-free survival, and overall survival were the same in both groups. All these results indicate that GPX1 expression does not influence the radiotherapy response nor survival.

Keywords: oxidative stress status, head and neck cancer, glutathione peroxidase, prognostic significance

\section{INTRODUCTION}

Cancer of the head and neck region represent the fifth most common form of cancer and caused 350,000 deaths per year $(1,2)$. Tumors of the head and neck have strong links to oxidative damage and oxidative stress, with tobacco and alcohol clearly defined as major etiologic factors.

So far, no reliable prognostic biological marker for the squamous cell carcinoma located in different subsites of the head and neck region has been identified and used in daily routine. In accordance with other authors, we believe that potential markers can be found among the parameters of oxidative stress $(3,4)$.

Therefore, in line with our previous studies pointing at the role of glutathione and associated enzymes as potential biological markers $(5,6)$, we have investigated relationships between GPx1 and prognosis of head and neck squamous cell carcinoma (HNSCC). 
By reducing hydrogen peroxide at the expense of oxidizing GSH to its disulfide form, GSSG, GPx1 is a major enzyme of the cellular antioxidant armada (3). It is present in cytosolic and mitochondrial compartments, but, in some cells, in peroxisomal compartments (7). GPx1 has been found to be more effective than catalase at protecting the cells again intracellular peroxides under many physiological conditions.

GPxl activity is often compared with glutathione reductase activity, which role is to maintain a constant level of GSH from GSSG for enzyme activity. Furthermore, GPx1 is highly upregulated during oxidative stress making it a suitable biomarker for oxidative stress (8). Therefore, in this retrospective study, we investigated the prognostic value of GPx1 expression in head and neck cancers.

\section{MATERIALS AND METHODS}

\section{Study Cohort}

The study cohort consisted out of 87 HNSCC patients (73 males, 14 females, median age 58.2 years) who underwent definitive radiotherapy or concomitant chemoradiotherapy as primary oncological treatment at the University Hospital in Leuven. Treatment modality was based on the extent of the disease at initial presentation and performance status of the patient. Radiotherapy alone was initiated in 31 patients (36\%). All patients received 72 Gy of radiation; treatment was administered once a day, five times a week the first 4 weeks of therapy, the last 2 weeks two fractions per day were administered (9). Forty-nine of the 87 patients (56\%) received concomitant chemoherapy based on cisplatin $100 \mathrm{mg} / \mathrm{m}^{2}$ week 1 and week 4 . Six patients (7\%) were treated by radiotherapy with concurrent cetuximab. Cetuximab was chosen in those patients with contraindications for cisplatin. Median follow-up was 5.54 years (4.15-7.67).

The study was performed according to protocols approved by the Ethical board of the University Hospitals (Commissie Medische Ethiek van de Universitaire ziekenhuizen KULEUVEN), and all the patients provided inform consent. Histological examination of the tumor biopsies indicated squamous cell carcinomas in all cases. Human papillomavirus (HPV) and p16 status was determined as previously described (10).

\section{Immunohistochemistry of Tumor Biopsies}

For immunostaining of GPx1 (HPA044758; Sigma-Aldrich), routine formalin-fixed paraffin-embedded (FFPE) pretreatment tumor tissues, available for 87 HNSCC patients were used. Briefly, $4-\mu \mathrm{m}$ FFPE tumor sections were deparaffinized in Ultraclear and rehydrated in $100 \%$ ethanol. Endogenous peroxidases were blocked by using $0.3 \% \mathrm{H}_{2} \mathrm{O}_{2}$ in Methanol solution. Heat-induced antigen retrieval ( $\mathrm{pH}$ 6) was performed. Immunodetection was performed with EnVision HRP Anti-Rabbit secondary antibody and peroxidase/DAB kit (Dako). Sections were counterstained with hematoxylin. Scoring of GPx 1 was performed by multiplying the intensity (Table 1) and percentage of tumor cells (Table 2). High GPx1-expressing tumors were defined by a high-intensity score (3) and high-scoring categories ( $>3$ ) according to the percentage of GPx1 positive tumoral cells $(>50 \%)$.
TABLE 1 | Scoring categories according to the intensity of GPx1 labeling in the tumor.

\begin{tabular}{lc}
\hline Intensity & Score \\
\hline Low & 1 \\
Medium & 2 \\
High & 3 \\
\hline
\end{tabular}

TABLE 2 | Scoring categories according to the percentages of GPx1 positive cells in the tumor.

\begin{tabular}{lc}
\hline Percentage of stained cells & Scoring \\
\hline$<10$ & 0 \\
$10-25$ & 1 \\
$25-50$ & 2 \\
$50-75$ & 3 \\
$>75$ & 4 \\
\hline
\end{tabular}

\section{Statistical Analysis}

Differences in GPx1 high- and low-expression groups were analyzed using the Chi-square test in case of categorical predictors, whereas one-way ANOVA was used in cases of continuous predictors. Former smokers are defined as patients who stopped smoking longer than 1 year prior to the date of diagnosis. Local control (LC) and locoregional control (LRC) were defined as the time between the start of treatment and the date of local or locoregional recurrence. Time between the start of treatment and disease recurrence or death expressed the disease-free survival (DFS). Overall survival (OS) was determinated by the time between the initial treatment and death of any cause. The survival curves were generated and calculated by using, respectively, the Kaplan-Meier method and the log-rank test. All analyses were performed using the Statistica software version 12, and all test were considered significant when $p \leq 0.05$.

\section{RESULTS}

A total of 87 pretreatment patient tumor samples were stained for GPx1 (Figure 1). The baseline patient and tumor characteristics according to GPx1 expression are summarized in Table 3. Twentyeight percent of the total amount of patients (24 out of 87) showed a high expression of GPx1. The majority of patients (72\%) showed low expression levels of GPx1. The age, treatment modality, and $\mathrm{HPV} / \mathrm{p} 16$ status did not differ between the two different groups. No relation was found between GPx1 expression and smoking history. Also, no significant differences were found in nodal status between the two groups. However, a significant negative correlation between T-status and GPx1 $(r=-0.23 ; p=0.028)$ was noted. About $75 \%$ of the T3-T4 tumors were considered GPx1 low-expressing tumors, while low GPx1 expression was only seen in $25 \%$ of the T1-T2 tumors. Also, significant differences were found between the GPx1 groups and different tumor sites.

Assessment of GPx1 expression and outcome parameters such as LC (Figure 2A), DFS (Figure 2B), OS (Figure 2C), and LRC (Figure 2D) did not result in significant differences.

All these results indicate that GPx1 expression does not influence the radiotherapy response nor the survival. 


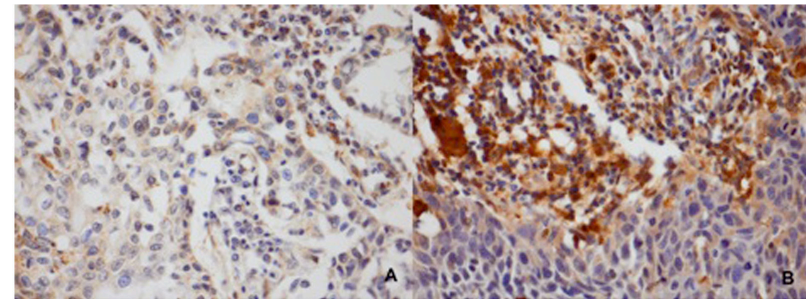

FIGURE 1 | Classification of the GPx1 staining according to intensity and the percentage of stained cells. (A) Tumors classified as low levels of GPx1. (B) Tumor classified as high levels of GPx1

TABLE 3 | Patient and tumor characteristics by GPx1 expression.

\begin{tabular}{|c|c|c|c|c|c|c|c|}
\hline \multirow{2}{*}{$\begin{array}{l}\text { Data } \\
\text { No of patients }\end{array}$} & \multicolumn{2}{|c|}{ GPx1 high } & \multicolumn{2}{|c|}{ GPx1 low } & \multicolumn{2}{|c|}{ All patients } & \multirow[t]{2}{*}{$p$-Value } \\
\hline & $\begin{array}{l}\text { No. } \\
24\end{array}$ & $\begin{array}{l}\% \\
28\end{array}$ & $\begin{array}{l}\text { No. } \\
63\end{array}$ & $\begin{array}{l}\% \\
72\end{array}$ & $\begin{array}{l}\text { No. } \\
87\end{array}$ & $\%$ & \\
\hline Gender & & & & & & & NS \\
\hline Male & 19 & 79 & 54 & 86 & 73 & 72 & \\
\hline Female & 5 & 21 & 9 & 14 & 14 & 28 & \\
\hline Age, years & & & & & & & NS \\
\hline Median (range) & \multicolumn{2}{|c|}{$58.6(46-76)$} & \multicolumn{2}{|c|}{$58.0(43-78)$} & \multicolumn{2}{|c|}{$58.2(43-78)$} & \\
\hline Nodal status & & & & & & & NS \\
\hline N0/N1 & 8 & 33 & 25 & 40 & 33 & 38 & \\
\hline N2/N3 & 16 & 67 & 38 & 60 & 54 & 62 & \\
\hline Tumor status & & & & & & & $p=0.028$ \\
\hline $\mathrm{T} 1 / \mathrm{T} 2$ & 12 & 50 & 16 & 25 & 28 & 32 & \\
\hline $\mathrm{T} 3 / \mathrm{T} 4$ & 12 & 50 & 47 & 75 & 59 & 68 & \\
\hline Disease stage & & & & & & & NS \\
\hline$|-| \mid$ & 1 & 4 & 2 & 3 & 3 & 3 & \\
\hline III-IV & 23 & 96 & 61 & 97 & 84 & 97 & \\
\hline Tumor site & & & & & & & $p=0.033$ \\
\hline Soft palate & 1 & 4 & 2 & 3 & 3 & 3 & \\
\hline Tonsil & 8 & 33 & 19 & 30 & 27 & 30 & \\
\hline BOT/vallecula & 14 & 59 & 19 & 30 & 33 & 37 & \\
\hline Pharyngeal wall & 0 & 0 & 9 & 15 & 9 & 14 & \\
\hline Unknown & 1 & 4 & 14 & 22 & 15 & 16 & \\
\hline $\begin{array}{l}\text { Human } \\
\text { papillomavirus (HPV) }\end{array}$ & & & & & & & NS \\
\hline HPV negative & 15 & 63 & 35 & 56 & 50 & 57 & \\
\hline HPV positive & 5 & 21 & 8 & 13 & 13 & 15 & \\
\hline Unknown & 4 & 16 & 20 & 31 & 24 & 28 & \\
\hline Treatment & & & & & & & NS \\
\hline RT & 8 & 33 & 23 & 36 & 31 & 36 & \\
\hline $\mathrm{RT}+$ cetuximab & 1 & 4 & 5 & 8 & 6 & 7 & \\
\hline $\mathrm{RT}+\mathrm{CT}$ & 15 & 63 & 34 & 54 & 49 & 56 & \\
\hline Unknown & 0 & 0 & 1 & 2 & 1 & 1 & \\
\hline Smoking history & & & & & & & NS \\
\hline Never & 4 & 17 & 4 & 6 & 8 & 9 & \\
\hline Former & 5 & 21 & 11 & 17 & 16 & 18 & \\
\hline Current & 12 & 50 & 45 & 72 & 57 & 66 & \\
\hline Unknown & 3 & 12 & 3 & 5 & 6 & 7 & \\
\hline p16 & & & & & & & NS \\
\hline Negative & 3 & 12 & 19 & 30 & 22 & 25 & \\
\hline Nuclear & 7 & 29 & 18 & 29 & 25 & 29 & \\
\hline Cytoplasmic & 10 & 42 & 15 & 24 & 25 & 29 & \\
\hline Unknown & 4 & 17 & 11 & 17 & 15 & 17 & \\
\hline
\end{tabular}

NS, not significant; BOT, base of tongue; RT, radiotherapy; CT, chemotherapy.

\section{DISCUSSION}

Cancer of the head and neck region and their treatment protocols still lack well-established prognostic biological markers (11). It is well known that non-HPV-related oropharyngeal cancers and HPV-related cancers are distinct entities concerning tumor biology and clinical outcome. For oropharyngeal cancers, HPV is a well-established prognostic marker to radiotherapy response (10) and survival. For non-oropharyngeal cancers, the HPV status is not of prognostic significance $(12,13)$ and, currently, there is no general guidance to adapt treatment strategies to HPV status. In line with previous publications, we believe that parameters of oxidative stress could offer useful potential markers $(3,4)$. Previously, we confirmed this hypothesis by demonstrating that a significant redox imbalance in head and neck cancer patients could offer a prognostic value (14).

Moreover, we reported a strong correlation between the contents of oxidized and reduced glutathione (GSSG/GSH) in tumors and the nodal status of our head and neck patients. A lower ratio GSSG/GSH was observed in tumor tissue of N0 patients, while a higher ratio GSSG/GSH was determined in positive node patients. This might suggest that high GSSH/GSH ratio tumors have a more aggressive phenotype caused by the oxidative stress, leading to a tendency to more local spread. Furthermore, compared to patients who showed high levels of oxidative stress ratio GSSH/GSH, patients with lower ratio GSSG/GSH showed lower risk of locoregional recurrence of their tumor after treatment. This again suggests that tumors with high-oxidative stress status are more aggressive.

These data lead us to extent our research by checking other components of the cellular antioxidant armada. In line with previous studies pointing to the role of glutathione-associated enzymes as potential markers, we have investigated relationships between GPx1 and prognosis of HNSCC.

Based on preclinical and clinical studies on glutathione peroxidase levels in tumors $(15,16)$, glutathione peroxidase, an important member of the defensive machinery against oxidative stress, was investigated.

No correlation was found between HPV status and the expression of GPx1. Furthermore, p16 status and localization did not differ between the groups of treated patients. A possible explanation could be the confounding effect of T-status on outcome. Our results contrast with the results presented by other authors. Williams et al. (17) suggested, in their study, that high risk types of human papillomavirus increased the level of reactive oxygen species, associated with a decrease of antioxidant enzyme GPx1 expression. This increased oxidative stress led to higher levels of DNA damage.

Furthermore, in contrast with our previous results, no significant correlation was found between the tumors expressing GPx1, found to be more effective than catalase at removing intracellular peroxides under many physiological conditions, and the nodal status. By contrast, Han et al. (18) found that high GPx1-expressing tumors were associated with extensive lymph node metastasis.

However, a significant correlation between T-status and GPx1 expression in tumors $(p=0.03)$ was found. The patients with tumors showing a low GPx1 expression had more tumors staged 

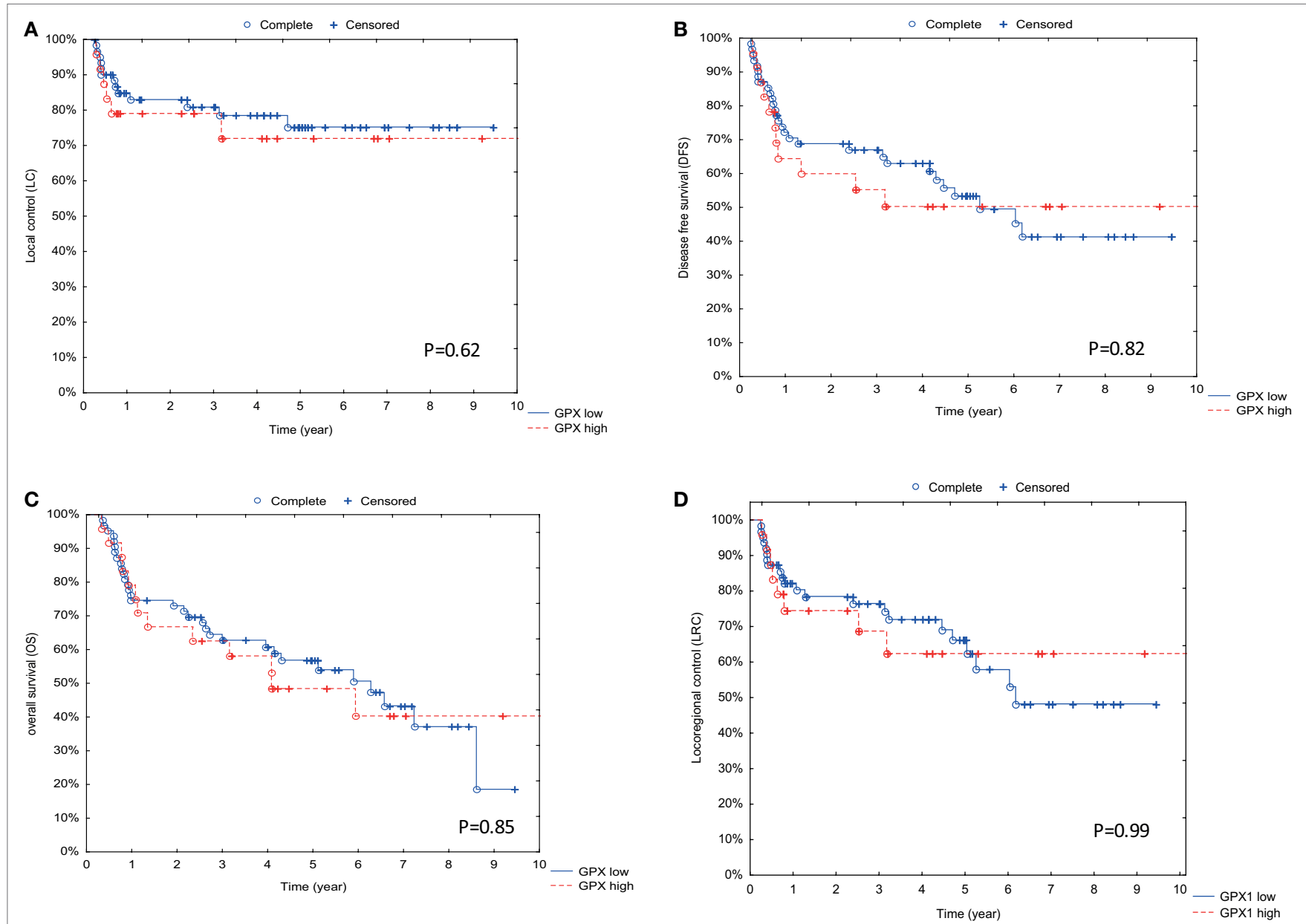

FIGURE 2 | Association between GPx1 expression and outcome parameters. (A) Correlation between GPx1 expression and outcome with local control (LC) as endpoint. On the $y$-axis is the percentage of patients with LC displayed, and on the $x$-axis is the time in years displayed. (B) Correlation between GPx1 expression and outcome with disease-free survival (DFS) as endpoint. On the $y$-axis is the percentage of patients with DFS displayed, and on the $x$-axis is the time in years displayed. (C) Correlation between GPx1 expression and outcome with overall survival (OS) as endpoint. (D) Correlation between GPx1 expression and outcome with locoregional control as endpoint. On the $y$-axis is the percentage of patients with OS displayed, and on the $x$-axis is the time in years displayed. $p$ Values are determined by log-rank tests.

T3-T4. Moreover, we observed a significant correlation between tumors expressing GPx1 and the tumor localization. The patients with low GPx1-expressing tumors had more tumors located at the tonsil.

The function of GPx1 is to promote migration, proliferation, and tumor cell invasion, conditioning a potential not yet defined prognostic role, in cancer patients (19). The results published by Han et al support these findings, showing that expression of GPx1 was related to good outcome $(p=0.03)$ in patients with human gastric adenocarcinoma.

In hepatocellular carcinoma, Zmorzynski et al. (20) found that high GPx1-expressing tumors were correlated with a shorter survival time as in patients with prostate cancer.

Moreover, high GPx1-expressing tumors could be responsible for cisplatin resistance as observed in esophageal cancer cell lines (21). Similarly, Zhao et al. observed that GPx1 may serve as a molecular marker for monitoring bladder cancer recurrence (22). In patients with gastric cancer, low expressed
GPx1 tumors were associated with aggressiveness and poor survival (23).

Interestingly, our results suggest the absence of the prognostic value of GPx1 expression in head and neck cancers. No significant differences were found in any of the other characteristics: LC, LRC, DFS, and OS. A possible explanation would be that a small biopsy of the tumor does not represent the whole tumor, taking into account the issue of tumor heterogeneity. Moreover, since, we only had the availability of small paraffin-embedded biopsies, only one immunohistochemistry staining for GPx1 could be performed. Several other markers of the oxidative stress pathway could be investigated (24). New research into others markers of oxidative stress seems valuable.

To determine the cellular antioxidant capacity, next to other isoforms of glutathione peroxidase as $\mathrm{GPx} 4$, the expression of other important antioxidant enzymes, such as manganese superoxide dismutase and its isoform SOD2 will be of interest as proven in preliminary animal studies (25). 
To elucidate the potential clinical significance of GPx1 observed in other solid tumors, large studies, analyzing multiple glutathione-associated enzymes in addition to GPx1, are needed.

\section{CONCLUSION}

After determining the levels of oxidative stress in 87 HNSCC patients, significant clinical differences were found between patients expressing high level of GPx1 and patients expressing low levels of GPx1. A significant negative correlation between T-stage and GPxl expression in tumors $(p=0.03)$ was found. The patients with tumors showing a low GPx1 expression had

\section{REFERENCES}

1. Ferlay J, Sbhin HR, Bray F, Forman D, Mathers C, Parkin DM. Estimates of worldwide burden of cancer in 2008: GLOBOCAN 2008. Int J Cancer (2010) 127:2893-917. doi:10.1002/ijc.25516

2. Jemal A, Siegel R, Xu J, Ward E. Cancer statistics, 2010. CA Cancer J Clin (2010) 60:277-300. doi:10.3322/caac.20073

3. Gamcsik MP, Kasibhatia MS, Teeter SD, Colvin OM. Glutathione levels in human tumors. Biomarkers (2012) 17(8):671-91. doi:10.3109/1354750X. 2012.715672

4. Salzman R, Pacal L, Kankova K, Tomandl J, Horakova Z, Tothova E, et al. High perioperative level of oxidative stress as a prognostic tool for identifying patients with a high risk of recurrence of head and neck squamous cell carcinoma. Int J Clin Oncol (2010) 15:565-70. doi:10.1007/s10147-010-0108-Z

5. Dequanter D, Van de Velde M, Nuyens V, Nagy N, Van Antwerpen P, Vanhamme L, et al. Assessment of oxidative stress in tumors and histologically normal mucosa from patients with head and neck squamous cell carcinoma: a preliminary study. Eur J Cancer Prev (2013) 6:558-60. doi:10.1097/CEJ. ob013e32836056dc

6. Dequanter D, Vandevelde M, Bar I, Nuyens V, Rousseau A, Nagy N, et al. Nuclear localization of glutamate-cysteine ligase is associated with proliferation in head and neck squamous cell carcinoma. Oncol Lett (2016) 11(6):3660-8. doi:10.3892/ol.2016.4458

7. Lubos E, Loscalzo J, Handy DE. Glutathione peroxidase 1 in health and disease: from molecular mechanisms to therapeutic opportunities. Antioxid Redox Signal (2011) 15:1957-97. doi:10.1089/ars.2010.3586

8. Li S, Yan T, Yang JQ, Oberley TD, Oberley LW. The role of cellular glutathione peroxidase redox regulation in the suppression of tumor cell growth by manganese superoxide dismutase. Cancer Res (2000) 60:3927-39.

9. Nuyts S, Dirix P, Hermans R, Poorten VV, Delaere P, Weltens C, et al. Early experience with a hybrid accelerated radiotherapy schedule for locally advanced head and neck cancer. Head Neck (2007) 29:720-30. doi:10.1002/ hed. 20565

10. Dok R, Abbasi Asbagh L, Van Limbergen EJ, Sablina A, Nuyts S. Nuclear p16 INK4a expression predicts enhanced radiation response in head and neck cancers. Oncotarget (2016) 7(25):38785-95. doi:10.18632/oncotarget.9609

11. Brauswetter D, Birtalan E, Danos K, Kocsis A, Krenacs T, Timar J, et al. p16INK4 expression is of prognostic and predictive value in oropharyngeal cancers independent of human papillomavirus: a Hungarian study. Eur Arch Otorhinolaryngol (2017) 274(4):1959-65. doi:10.1007/s00405-016-4412-8

12. Liang C, Marsit CJ, McClean MD, Nelson HH, Christensen BC, Haddad RI, et al. Biomarkers of HPV in head and neck squamous cell carcinoma. Cancer Res (2012) 72(19):5004-13. doi:10.1158/0008-5472.CAN-11-3277

13. Fakhry C, Westra WH, Wang SJ, van Zante A, Zhang Y, Rettig E, et al. The prognostic role of sex, race, and human papillomavirus in oropharyngeal and nonoropharyngeal head and neck squamous cell cancer. Cancer (2017) 123(9):1566-75. doi:10.1002/cncr.30353

14. Dequanter D, Dok R, Nuyts S. Basal oxidative stress ratio in head and neck squamous cell carcinoma correlates with nodal metastatic spread in patients under therapy. Onco Targets Ther (2017) 10:259-63. doi:10.2147/OTT. S118980 more tumors staged T3-T4. Moreover, we observed a significant correlation between tumors expressing GPx1 and the tumor localization. The patients with low-expressing GPx1 tumors had more tumors located at the tonsil. Interestingly, no significant differences were found in any of the outcome characteristics: LC, LRC, DFS, and OS, suggesting the absence of the prognostic value of GPx1 expression is HNSCC.

\section{AUTHOR CONTRIBUTIONS}

$\mathrm{DD}, \mathrm{RD}, \mathrm{LK}$, and SN contributed equally to the redcation of the manuscript.

15. Coskun C, Verim A, Farooqi AA, Turan S, Mezani B, Kucukhuseyin O, et al. Are the possible associations between MnSOD and GPx1 gen variants for laryngeal cancer risk or disease progression? Cell Mol Biol (2016) 30: 25-30.

16. Guo H, Seixas-Silva JA, Epperly MW, Gretton JE, Shin DM, Bar-Sagi D, et al. Prevention of radiation-induced oral cavity mucositis by plasmid/ liposome delivery of the human manganese superoxide dismutase (SOD2) transgene. Radiat Res (2003) 159:361-70. doi:10.1667/0033-7587(2003)159 0361:PORIOC]2.0.CO;2

17. Williams VM, Filippova M, Filippov V, Payne KJ, Duerksen-Hughes P. Human papillomavirus type $16 \mathrm{E} 6$ induces oxidative stress and DNA damage. J Virol (2014) 88:6751-61. doi:10.1128/JVI.03355-13

18. Han JJ, Xie DR, Way LL, Wu GF, Sun Q, Chen YX, et al. Significance of glutathione peroxidase 1 and caudal related homeodomain transcription factor in human gastric adenocarcinoma. Gastroenterol Res Pract (2013) 2013:380193. doi:10.1155/2013/380193

19. Dalle-Donne I, Rossi R, Colombo R, Giustarini D, Milzani A. Biomarkers of oxidative damage in human disease. Clin Chem (2006) 52:601-23. doi:10.1373/ clinchem.2005.061408

20. Zmorzynski S, Swidersko-Kolacz G, Koczkodaj D, Filip DD. Significance of polymorphism and expression of enzyme encoding genes related to glutathione in hematopoietic cancers and solid tumors. Biomed Res Int (2015) 2015:853573. doi:10.1115/2015/853573

21. Gan X, Chen B, Shen Z, Liu Y, Li H, Xie X, et al. High GPx1 expression promotes esophageal squamous cell carcinoma invasion, migration, proliferation and cisplatin-resistance but can be reduced by vitamin D. Int J Clin Exp Med (2014) 9:2530-40.

22. Zhao H, Liang D, Grossman HB, Wu X. Glutathione peroxidase 1 gene polymorphism and risk of recurrence in patients with superficial bladder cancer. Urology (2005) 66:769-74. doi:10.1016/j.urology.2005.04.033

23. Min SY, Kim HS, Juy EJ, Juy EJ, Jee CD, Kim WH. Prognostic significance of glutathione peroxidase 1 downregulation and correlation with aberrant promoter methylation in human gastric cancer. Anticancer Res (2012) 32:3169-76.

24. Ho E, Karimi Galougahi K, Liu C-C, Bhindi R, Figtree GA. Biological markers of oxidative stress: applications to cardiovascular research and practice. Redox Biol (2013) 1:483-91. doi:10.1016/j.redox.2013.07.006

25. Epperly MW, Wegner R, Kanai AJ, Kagan V, Greenberger EE, Nie S, et al Effects of MnSOD-plasmid liposome gen therapy on antioxidant levels in irradiated murine oral cavity orthotopic tumors. Radiat Res (2007) 167(3):289-97. doi:10.1667/RR0761.1

Conflict of Interest Statement: The authors declare that the research was conducted in the absence of any commercial or financial relationships that could be construed as a potential conflict of interest.

Copyright (c) 2017 Dequanter, Dok, Koolen, Vander Poorten and Nuyts. This is an open-access article distributed under the terms of the Creative Commons Attribution License (CC BY). The use, distribution or reproduction in other forums is permitted, provided the original author(s) or licensor are credited and that the original publication in this journal is cited, in accordance with accepted academic practice. No use, distribution or reproduction is permitted which does not comply with these terms. 